\title{
Tryptophan Hydroxylase and Serotonin Receptors 5-HT1A, 5-HT2A, 5-HT3A, 5-HT4, 5-HT5A, 5-HT6 and 5-HT7 in Frog and Turtle Retina: an Immunofluorescence Study
}

\author{
Liliya Vitanova*, Desislava Zhekova, Petia Kupenova \\ Dept. Physiology, Medical University, Sofia, Bulgaria \\ Email: lilyvita@abv.bg
}

\begin{abstract}
Serotonin (5-HT) is one of the major monoamines in the brain. It is also found in the retina, a part of the brain, where a subgroup of amacrine cells are considered to be the sole retinal source of 5-HT. The data, obtained so far, about the serotonin receptors' function are contradictory. Therefore, our aim was to study the distribution of the 5-HT synthesizing neurons and the serotonin receptors from 5-HT1A to 5-HT7 in frog and turtle retinas, using the indirect immunofluorescent method. We found strong Tryptophan hydroxylase immunoreactivity in many amacrine and bipolar cells. Some horizontal, ganglion and glial cells were also stained, as well as a bundle of parallel axons in the proximal retina. All 5-HT receptors were also very well expressed. Our data show that the serotonin retinal sources are more numerous than was previously thought. The great variety of receptors expressed implies that serotonin may fulfill different functions, serving both as neuro- and glio-transmitter/modulator.
\end{abstract}

Keywords: Serotonin, serotonin receptors, tryptophan hydroxylase, retina, frog, turtle

\section{Introduction}

Serotoninergic (5-hydroxytryptaminergic) neurotransmission appears relatively early during the development. Serotonin, along with dopamine, is one of the major brain monoamines in many species. In central neural system (CNS) it is widely distributed in the forebrain, participating in complex neuronal networks related to mood, pain perception, learning, memory, reward etc. Deficits in the serotoninergic neurotransmission appear to play a major role in depression [1].

Serotonin is also found in the retina, which is known to be a part of CNS. The retinal studies on serotonin are important in both fundamental and clinical aspects. In fundamental aspect the retinal serotonin studies would allow a better understanding of its participation in the CNS (and the retina) information processing. Furthermore, these studies would also have clinical significance. Recent research showed that alterations in the CNS serotonin level can affect ERG responses [2]. Therefore, electroretinography as a method could be a useful tool in diagnostics of some psychiatric disorders. Indeed, recent study by Dr. R. F. Miller using ERG showed that earlier development of brain schizophrenia may be recognized using retinal electric activity and the analysis of the ERG sub-waves. In addition, new research on serotonin, its derivates and some of its receptors [3, 4] revealed their neuroprotective role on the retina, which may be of great importance for clinical treatment of some retinal diseases.

The focus of our study was the participation of serotoninergic transmission in the visual information processing. Serotonin in the retina appears relatively early during the phyllo- and ontogenesis. It is proved to exist in goldfish, frog, lizard, turtle, chick, rabbit, cat and bovine retinas [5 - 11]. Some of the authors found that serotonin is better represented in lower vertebrate retinas as compared to higher vertebrate ones [5].

The main sources of serotonin in all species are the serotoninergic amacrine cells [12 - 14]. There is no controversy over this point, while the data concerning additional localizations of serotonin in the retina vary considerably. Serotonin immunoreactivity has been found in a subgroup of bipolar cells [13, 15 - 19]. In addition, it has been shown that some horizontal cells are able to accumulate serotonin from a 
mixture of exogenous substances [20,21]. At present, the great majority of authors assume that both serotonin synthesizing and serotonin accumulating neurons are present in the retina. The amacrine cells which are proved to possess enzymes mandatory for serotonin synthesis (mainly tryptophan hydroxylase), belong to the so called serotonin synthesizing neurons, while the bipolar cells which are only able to accumulate serotonin, but not to synthesize it because of lack of these enzymes, are serotonin accumulating neurons [22 - 24].

In contrast to serotonin, the serotonin receptors in the retina are poorly studied. Data exist that the serotonin receptor 5-HT1A in the goldfish and rabbit retina is localized on the ganglion cells, where it is involved in controlling their spike activity [25 - 26]. Recently, Pootanakit and Brunken [27] and Pennesi et al. [28] showed presence of 5-HT1A receptor in mammalian retina as well. The 5-HT2A is studied in the bullfrog, rat and rabbit retinas [29, 30]. According to Han et al. [30], it is better expressed in the bullfrog retina as compared to the rat one, where it is almost indistinguishable by immunocytochemistry. The presence of 5-HT3A receptor is proved immunocytochemically in the rat, rabbit and human retina with localization on the photoreceptors [31]. In addition, in an electrophysiological study on mammalian retina with 5-HT3A receptor agonists and antagonists, Brunken and Jin [32] find that one and the same substance causes opposite effects on the on- and off- ganglion cells activity and suppose that the 5HT3A receptor is involved in maintaining the balance between the on- and off- channels.

We did not find any data on the possible retinal distribution and/or function of 5-HT4, 5-HT5A and 5-HT6 receptors, although they were proved to exist in variable parts of CNS in different species, including humans, participating in nociception, food intake, behavior etc. [33 - 36]. As far as the 5-HT7 receptor is concerned, its receptor transcript has been already identified by means of RT-PCR in rat and rabbit retinas [27]. In teleost retina it is proved to modulate the ganglion cells spike generation [25]. Data also exist that the 5-HT7 receptor mediates the retinal input to the suprachiasmatic nucleus, the site of the "biological clock" in the body [37, 38].

\section{$2 \quad$ Material and Methods}

All procedures on a frog and a turtle were performed in accordance with the guidelines of the Ethical commission of Medical University Sofia, Bulgaria and the EU legislation.

\subsection{Tissue Preparation}

Retinae of the frog Rana ridibunda and the turtle Emys orbicularis were used. The animals were deeply anesthetized in water containing tricain-methansulphonate $(500 \mathrm{mg} / \mathrm{L})$ and decapitated. The eyes were dissected, and the posterior eyecups with the retinas were immediately immersed in $4 \%(\mathrm{w} / \mathrm{v})$ paraformaldehyde in 0.1 M phosphate buffer for 15-30 min. After fixation, the retinas were dissected from the eyecups and cryoprotected in graded sucrose solutions (10\%, 20\%, and 30\% w/v). Cryostat sections were cut at $14 \mu \mathrm{m}$ and stored at $-20{ }^{\circ} \mathrm{C}$.

\subsection{Antibodies Used}

The following primary antibodies were used:

1. A polyclonal rabbit antibody Anti-Serotonin Transporter (5-hydroxytryptamine; 5-HT Transporter (STT) (Merck-Millipore) - recognizes the serotonin transporter protein. Dilution 1:200.

2. A polyclonal rabbit antibody Anti-tryptophan hydroxylase TRYPH (H-60) (Santa-Cruz Biotechnology) - recognizes aminoacids 385- 437 at the C-terminus of the enzyme tryptophan hydroxylase of human origin. It is also recommended for detection of TRYPH in additional species. Dilution 1:100.

3. A polyclonal goat antibody Anti-tryptophan hydroxylase (Santa-Cruz Biotechnology) - raised against the internal region of the enzyme tryptophan hydroxylase. Dilution 1:100.

4. A polyclonal rabbit antibody anti SR-1A (H-119) (Santa-Cruz Biotechnology) - raised against aminoacids 218 - 336 of serotonin receptor SR-1A of human origin. It is also recommended for detection of SR-1A in additional species. Dilution 1:100. 
5. An anti 5-Hydroxytryptamine Receptor 2A antibody (rabbit) - peptide KKSLNGQPGSGDWRRC, part of the rat 5-HT1A receptor (a sample copy from Alomon Labs, Jerusalem BioPark, supplied with its corresponding synthetic antigen). Dilution 1:100.

6. A monoclonal mouse antibody anti SR-2A (A-4) (Santa-Cruz Biotechnology) - raised against aminoacids 1- 75 mapping within the N-terminal extracellular domain of the serotonin receptor SR-2A of human origin. Dilution 1:100.

7. An anti -5-Hydroxytryptamine Receptor 2A antibody (rabbit) - peptide (C)SEASNWTIDAENR, part of the N-terminus of rat 5-HT 1A receptor (a sample copy from Alomon Labs, Jerusalem BioPark, supplied with its corresponding synthetic antigen). Dilution 1:100.

8. A monoclonal mouse antibody anti SR-3A (A-9) (Santa-Cruz Biotechnology) - raised against aminoacids 341- 478 at the C-terminus of the serotonin receptor SR-3A of human origin. Dilution 1:100. 9. A polyclonal rabbit antibody anti SR-3A (H-138) (Santa-Cruz Biotechnology) - raised against aminoacids 341- 478 at the C-terminus of the serotonin receptor SR-3A of human origin. Dilution 1:100. 10. A polyclonal goat antibody SR-4 (N-18) (Santa-Cruz Biotechnology) - raised against a peptide mapping within a cytoplasmic domain of the serotonin receptor SR-4 of human origin. Dilution 1:100.

11. A monoclonal mouse antibody anti SR-5A (D-2) (Santa-Cruz Biotechnology) - raised against aminoacids 1- 57 mapping at the N-terminal of the serotonin receptor SR-5 of human origin. Dilution $1: 100$.

12. A polyclonal rabbit antibody anti SR-6 (H-143) (Santa-Cruz Biotechnology) - raised against aminoacids 141- 283 mapping within an internal region of the serotonin receptor SR-6 of human origin. Dilution 1:100.

13. A polyclonal rabbit antibody anti SR-7 (H-81) (Santa-Cruz Biotechnology) - raised against aminoacids 1-81 within the N- terminal extracellular domain of the serotonin receptor SR-7 of human origin. Dilution 1:100.

14. A monoclonal mouse antibody Anti-Vimentin (clone V9) (Merck-Millipore) - a marker for glial staining; recognizes a $57-60 \mathrm{kDA}$ protein. Dilution 1:100.

15. Calretinin - a polyclonal rabbit antibody, kind gift from prof. N. Cuenca (Alicante, Spain). Dilution 1: 1000 .

16. Calbindin - a polyclonal rabbit antibody, kind gift from prof. N. Cuenca (Alicante, Spain). Dilution 1: 1000

\subsection{Immunocytochemistry}

All antibodies were diluted in incubation solution, containing $0.5 \%$ Triton $\mathrm{X}-100,3 \%$ normal goat serum and $96.5 \%$ phosphate buffered saline (PBS) with $\mathrm{pH}=7.4$. Immunocytochemical labeling was performed by the indirect immunocytochemical method. First, the retinal sections were incubating overnight in the above mentioned primary antibodies solutions. After washing $(3 \times 10 \mathrm{~min})$, 1h incubation in one of the following secondary antibodies was performed: goat anti-rabbit, goat anti-mouse or donkey anti-goat coupled to either Alexa Fluor 488 or Alexa Fluor 594 causing green or red fluorescence, respectively (1:500, Molecular Probes, Life Technologies, USA). The control sections were processed in the same way, but the primary antibodies were omitted. No specific labeling was encountered in these sections.

All sections were examined by light microscopy, using the fluorescence microscopes Zeiss Photomicroscope III (Oberkochen, Germany) supplied by digital camera. The brightness and the contrast of the final images were adjusted using Adobe Photoshop 7.0 (Adobe Systems Inc., San Jose, CA, USA).

The specificity of staining in the experiments was also tested by using control antigens when it was possible. The control antigens $(1 \mu \mathrm{g})$ were preincubated with the corresponding primary antibodies $(1 \mu \mathrm{g})$ for at least 10 hours at room temperature, followed by the routine immunocytochemical procedure. Negative controls were obtained which confirmed the specificity of staining by the antibodies used.

The reported results were collected from more than 80 frog and 130 turtle retinal sections. Special care was taken the sections to represent both the central and peripheral retinal parts in order potential differences in the tyrosine hydroxylase and serotonin receptor distribution along the retina to be detected. 


\section{$3 \quad$ Results}

Our data showed that serotonin and serotonin receptors were very well expressed in both frog and turtle retinas. We succeeded to visualize a great number of "serotoninergic" structures, both neuronal and glial, as well as the receptors mediating the serotonin effects. They will be described consecutively.

\subsection{Serotoninergic Neurons Visualization: Tryptophan Hydroxylase Immunoreactivity}

We used two polyclonal antibodies (rabbit and goat) to stain the retina for serotonin. Both were directed against tryptophan hydroxylase (TrypH), the rate limiting enzyme for serotonin and melatonin synthesis from the amino acid tryptophan. The antibodies caused well expressed staining with similar character, which will be described in details further.

TrypH immunoreactivity in frog and turtle retinas was observed in almost all retinal layers (Fig. 1 and 2). A tendency for brighter staining of the distal layers than the proximal ones was sometimes evident in the turtle retina. Labels in the different layers will be described in details further.

In the photoreceptor layer we witnessed a well expressed visualization of the photoreceptors' outer segments (Fig. 1A). More distally, labels in the pigment epithelium could often be noticed.

In the outer nuclear layer (ONL), elongated oval shaped structures were distinguished in the turtle retina (Fig. 2D). Interconnection of these structures with some perikarya located in the inner nuclear layer (INL) could be tracked out in some of the retinal sections (Fig. 2C).

Labels in the inner nuclear layer (INL) were quite variable. In almost all retinal sections we noticed numerous cell bodies in the proximal part of the layer, some of them being located very close to the border with the inner plexiform layer (IPL) (Fig. 1B, Fig. 2). They had round or oval shape and different sizes. In some of the cases a thick process, subdivided into two branches, could be observed to leave the perikaryon and to head to the IPL (Fig. 2C and D).We interpreted these cell bodies as amacrine cells.
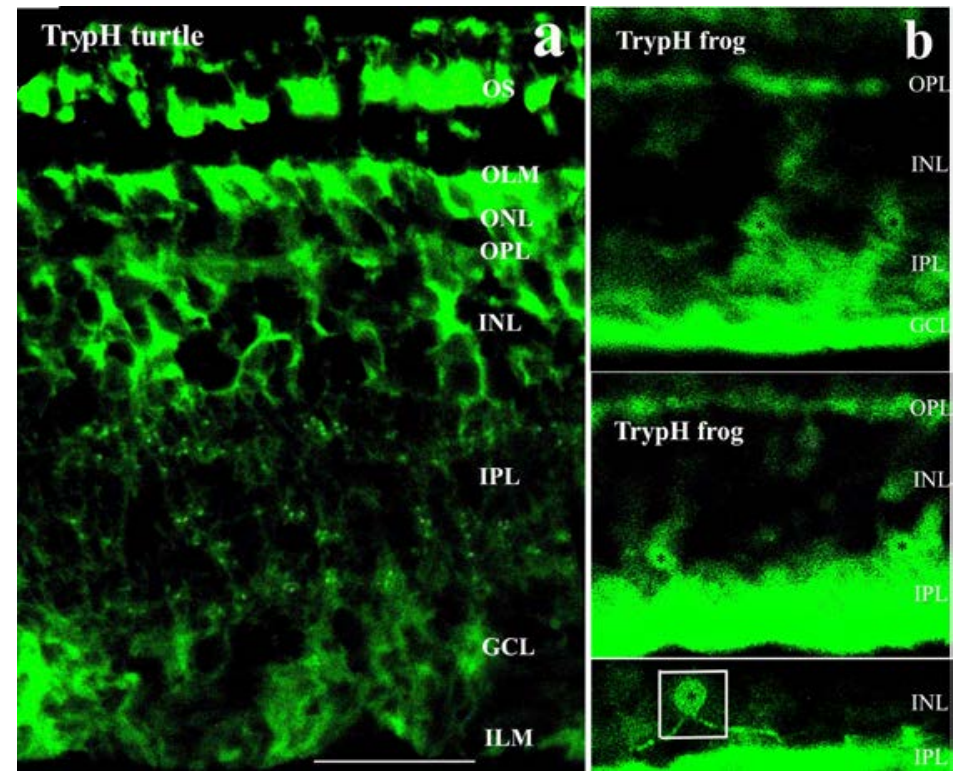

Figure 1. Tryptophan hydroxylase (TrypH) immunoreactivity in the frog and turtle retinas. Panel a: High power photomicrograph of a vertical retinal section through the turtle retina immunolabeled for tryptophan hydroxylase. Panel $b$ : Photomicrographs of three vertical retinal sections through the frog retina. The somata of TrypHimmunoreactive amacrine cells in the upper, middle and lower part of the panel are denoted by asterisks. The branching of an amacrine cell process into two ones, entering the IPL is shown in the lower part of the panel. The retinal layers are as follows: OS - outer segments of photoreceptors; OLM - outer limiting membrane; ONL - outer nuclear layer; OPL - outer plexiform layer; INL - inner nuclear layer; IPL - inner plexiform layer; GCL - ganglion 
cell layer; ILM - inner limiting membrane. Scale bar: panel a - $35 \mu \mathrm{m}$; panel b: upper and middle parts - $55 \mu \mathrm{m}$, lower part - $60 \mu \mathrm{m}$.

In the distal part of the layer, a row of cell bodies located between the middle of INL and the outer plexiform layer (OPL) could often be distinguished. These cell bodies had usually a pyriform shape. Many of them showed an axonal process that had a characteristic oblique course through the INL in direction to IPL. In the turtle retina, some of the pyriform shaped cell bodies were interconnected with the elongated structures in the ONL that were already mentioned (Fig. 2C and D). It gave us good ground to suppose that the cell bodies in the distal part of INL are bipolar cell, visualized together with their Landoldt clubs in the ONL.

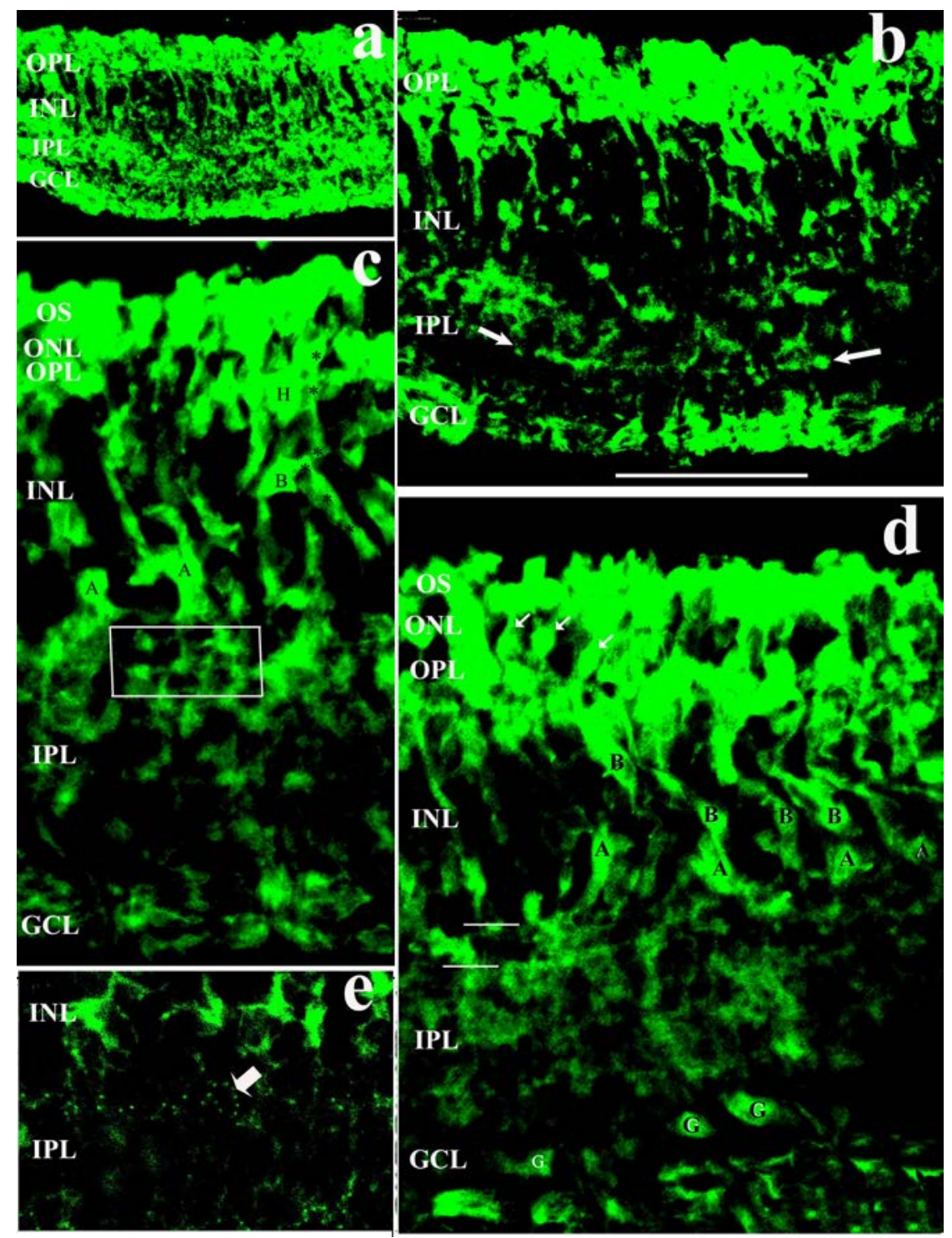

Figure 2. Tryptophan hydroxylase immunoreactivity in turtle retina. Low (a), middle (b) and high power photomicrographs (c, d and e) of vertical sections through the turtle retina immunolabeled for tryptophan hydroxylase are shown. In (b), a bar of TrypH immunoreactivity located in the middle part of IPL (most probably S3) is denoted by means of two arrows directed to each other. In the high power photomicrograph (c), a bipolar cell (B) and its processes, including the Landoldt club, can be followed (see the black asterisks). A TrypH immunoreactive amacrine $(\mathrm{A})$ and horizontal cell $(\mathrm{H})$ are shown as well. Notice also the varicosities along the TrypH-immunoreacrive fibers, enclosed by a rectangle in the IPL. On the high power photomicrograph in (d) a row 
of bipolar cells perikarya in INL (B) can be followed. The change of bipolars' perikarya position, which is evident, shows that the section passes near the visual streak. Three of the bipolar cells Landoldt clubs in ONL are denoted by arrows. Some of TrypH immunoreactive amacrine (A) and ganglion cells (G) are also shown. In the IPL, the trajectories of the amacrine cells processes projections were denoted by means of the two white lines. In (e), the "punctuate" character of the immunoreactivity in IPL is shown at high magnification. Several sublayers can be distinguished. A semi-ring shaped group of labels is shown by means of the small thick white arrow. The retinal layers are as follows: OS - outer segments of photoreceptors; ONL - outer nuclear layer; OPL - outer plexiform layer; INL - inner nuclear layer; IPL - inner plexiform layer; GCL - ganglion cell layer. Scale bar: a - $100 \mu \mathrm{m}$; b $60 \mu \mathrm{m} ; \mathrm{c}$ and $\mathrm{d}-40 \mu \mathrm{m}$; $\mathrm{e}-60 \mu \mathrm{m}$.

Bright immunofluorescence was also observed in both plexiform layers - OPL and IPL, the places where the synaptic contacts between the retinal neurons were formed. TrypH immunoreactivity in OPL was represented by numerous dots and patches (Fig. 1, Fig. 2). It may be supposed that some of these dots and patches are dendrites of the TrypH-immunoreactive bipolar cells whose cell bodies were visualized in the distal part of INL (Fig. 2D). In addition, single horizontal cells were also revealed by TrypH antibodies (Fig. 2C), and thus their participation in the OPL immunoreacivity cannot be excluded.

Concerning the immunoreactivity in IPL, it had more or less diffuse character in the frog retina, while in the turtle retina we succeeded to reveal several parallel bars (Fig. 1). The first of them was located immediately below the INL, in stratum $1\left(\mathrm{~S}_{1}\right)$. The second one was located approximately in the middle of INL, most probably in stratum $3\left(\mathrm{~S}_{3}\right)$. The third bar was usually observed in the most proximal part of IPL, in stratum $5\left(\mathrm{~S}_{5}\right)$ (Fig. $1 \mathrm{~A}$, Fig. $2 \mathrm{~B}$ and $2 \mathrm{E}$ ). Not all the bars were clearly expressed in each of the retinal sections.

TrypH- immunoreactivity in the $S_{1}$ was due mainly to the ramification of a class of amacrine cells whose cell bodies were located immediately above the border between INL and IPL. Two long processes, located at $180^{\circ}$ to each other were shown to leave the cell body and spread horizontally in $\mathrm{S}_{1}$ (Fig. $1 \mathrm{~B}$, Fig. 2C). Sometimes, subdivisions of these two processes were followed to ramify in $\mathrm{S}_{3}$ as well. A lot of varicosities could be seen along the length of all these fibers projecting in parallel in the IPL sublayers (Fig. 2C; Fig.2D).

In other cases, the TrypH- immunoreactivity in sublayers $\mathrm{S}_{1}$ and $\mathrm{S}_{3}$ had quite different character. No single processes with varicosities along their length could be followed. Instead of this, labels in $\mathrm{S}_{1}, \mathrm{~S}_{3}$ and $\mathrm{S}_{5}$ with more or less "punctate" character were observed, great number of them being organized in a bar in some of the sublayers mentioned. In some cases, several puncta formed a ring or arc along the bar (Fig. 1A, Fig. 2E). In our previous studies, we showed that the final endings of some bipolar cells' axons in the lower vertebrate retina formed rings in IPL [39]. Hence, we have good ground to admit that these ring or semi-ring shaped labels are axonal terminals of the TrypH- immunoreactive bipolar cells.

Single perikarya located sometimes in a row in the GCL were also labeled. They might be interpreted as displaced amacrine cells (Fig. 2D). However, as bundles of parallel optic nerve fibers were also labeled in some cases (Fig. 2B, Fig. 2C and 2D), it might be claimed that some of these perikarya belong to ganglion cells. Presence of TrypH- immunoreactive axons in the optic nerve is consistent with the findings of other authors [40], that the turtle retina possesses serotoninergic ganglion cells.

Well expressed staining of the glial Müller cells in the turtle retina was also noticed in some cases. Typical glial structures, as the outer and inner limiting membranes or the orthogonal array of particles were clearly visualized (Fig. 1A). In double labeling experiments, we proved colocalization to exist between the labels of the TrypH antibody in the above mentioned structures and those of the Vimentin antibody, a marker for glial staining (not shown here).

Recently, we studied the serotoninergic neurotransmission in the retina using an antibody directed to the serotonin transporter, a protein involved in the reuptake of serotonin [41]. The serotonin transporter, known as SERT in the literature, is a protein belonging to SLC 6 family of the recently described large group of organic cationic transporters OCT [42]. The serotonin transporter immunoreactivity, tested first on the turtle retina, is represented on Fig. 3, a photomicrograph from a previous paper of ours reprinted with the permission of the Bulgarian Academy of Sciences Publishing House [41]. Comparing the SERT- and TrypH- immunoreactivities, we find huge similarities between them. They both are characterized by synaptic and non-synaptic neuronal staining. Three types of retinal neurons amacrines, bipolars and horizontal cells, are proved to be both TrypH- and SERT-immunoreactive. The 
labels, caused by the two antibodies in both plexiform layers had also similar localization and appearance (compare the IPL labels in Fig. 1A, Fig. 2E and Fig. 3). This finding might be interpreted as a strong support to the concept that one and the same types of retinal neurons are able both to synthesize and release serotonin, on one hand, and to reuptake it from the extracellular space - on the other.

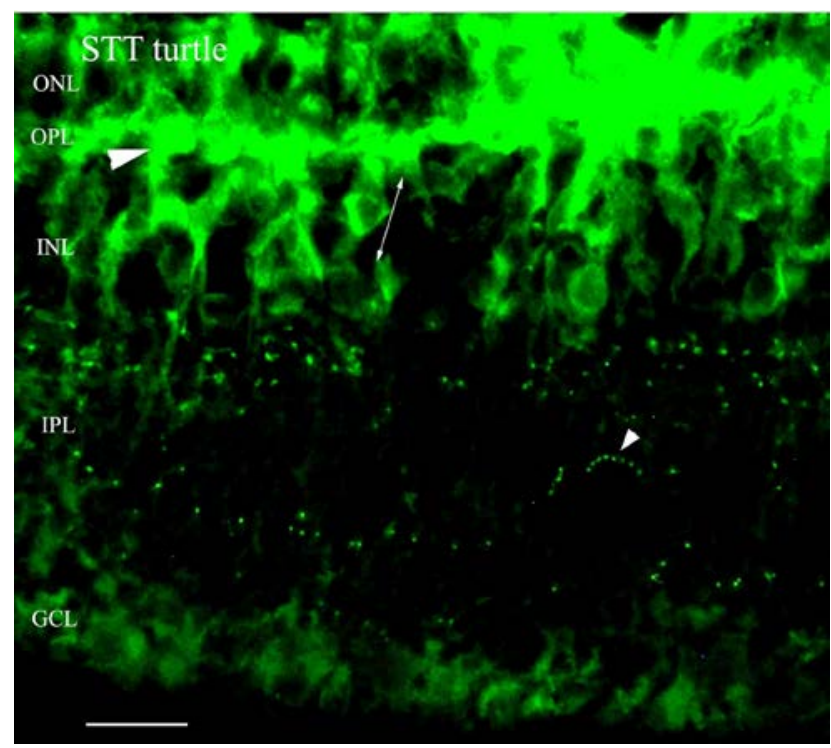

Figure 3. Serotonin transporter (SERT) imminoreactivity in the turtle retina. High power photomicrograph of a vertical retinal section through the turtle retina immunolabeled for serotonin transporter (STT, SERT). The perikaryon of a horizontal cell is denoted by large arrowhead. The oblique line with two arrows in the INL follows the projection direction of the nearest bipolar cell. The smaller arrowhead denotes labels in the IPL (S3 sublayer), forming the typical hemi- "ring-like" shaped axonal terminal of a bipolar cell. The retinal layers are denoted as follows: OS - outer segments of photoreceptors; OLM - outer limiting membrane; ONL - outer nuclear layer; OPL - outer plexiform layer; INL - inner nuclear layer; IPL - inner plexiform layer; GCL - ganglion cell layer; ILM inner limiting membrane. Scale bar: $20 \mu \mathrm{m}$.

The figure is reprinted from Vitanova and Zhekova (2015) with permission of the Bulgarian Academy of Sciences Publishing House.

\subsection{Serotonin Receptors Visualization}

All serotonin receptors studied were well expressed in the frog and turtle retinas. They will be described consecutively.

The SR1A antibody, directed to the 5-HT1A receptor, caused bright staining in both types of retinas. It allowed clear visualization of several different retinal layers simultaneously.

In the frog retina, the prominent "centre" in all photomicrographs was the bright and almost "diffuse" staining in IPL (Fig. 4A). However, at higher magnification at least two sublayers could be distinguished: upper $\left(\mathrm{S}_{1}\right)$ and lower $\left(\mathrm{S}_{5}\right)$. In some cases, a middle sublayer $\left(\mathrm{S}_{3}\right)$ could also be seen. Labels in the IPL were interpreted as a participation of 5-HT1A receptor in the proximal retina's synaptic transmission. A diversity of perikarya was seen in INL which almost "filled" the whole layer (Fig. 4A). Most numerous were the amacrine cells bodies. Bipolar cells with their pyriform shaped cell bodies and axons crossing INL in perpendicular or oblique direction were also labeled. Numerous cell bodies were visualized in GCL. Labels were found in horizontal cells and in the photoreceptors layer as well. 


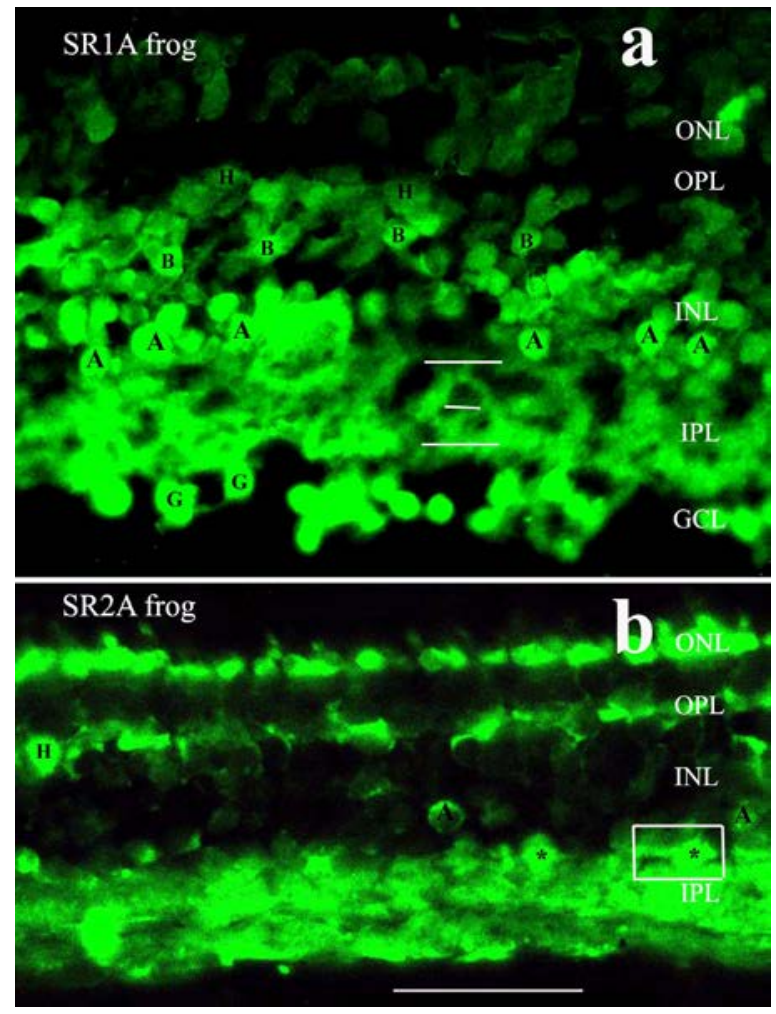

Figure 4. Photomicrographs of two vertical sections of frog retina, immunolabeled for 5-HT1A (antibody ST1A) receptor (a) and 5-HT2A (antibody ST2A) receptor (b). The numerous perikarya in the nuclear layers are denoted as follows: H - horizontal cell; B - bipolar cell; A - amacrine cell; G - ganglion cell. By means of three parallel white lines the sublayers in the IPL where the 5-HT1A -immunoreactivity is best expressed are denoted (A). Two amacrine cells, which cell bodies are almost embedded in the IPL upper part are denoted by asterisks. One of these amacrine cells, together with its two processes projecting at 1800 to each other is enclosed by a rectangle (B). The retinal layers are denoted as follows: ONL - outer nuclear layer; OPL - outer plexiform layer; INL - inner nuclear layer; IPL - inner plexiform layer; GCL - ganglion cell layer. Scale bar: a - 40 m; b - $50 \mu \mathrm{m}$.

In the turtle retina, the SR1A-immunofluorescence was dominated by numerous cell bodies in INL (Fig. 5A). Labels were found in perikarya of amacrine, horizontal and bipolar cells. A row of ganglion cells was also visualized. Parts of OPL could be followed. It was evident that the layer visualization was due predominantly to the processes of those horizontal cells, whose perikarya were brightly stained.

The SR2A antibody, directed to the 5-HT2A receptor, caused bright staining with predominantly synaptic character. Both plexiformed layers in the frog retina were very clear defined (Fig. 4B). Single perikarya belonging to amacrine and horizontal cells, were present as well. Some of the amacrine cells bodies (denoted by asterisks) were almost embedded in the most superficial layer of IPL, together with their two processes located at $180^{\circ}$ to each other. In the turtle retina, both plexiform and nuclear layers were stained. A tendency for subdivision of IPL in two sublayers (proximal and distal ones) was observed. Many perikarya, belonging to amacrine, bipolar and horizontal cells (Fig. 5B), were also labeled. 


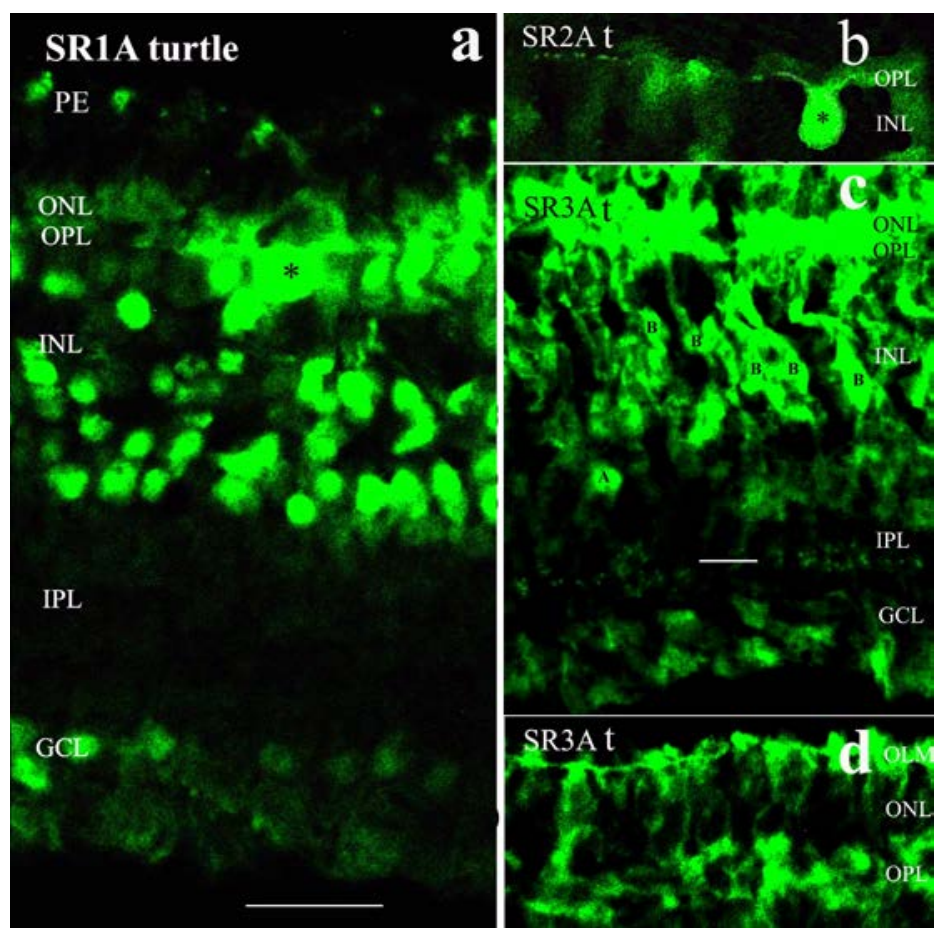

Figure 5. Photomicrographs of vertical sections of the turtle retina immunolabeled for 5-HT 1A (ST 1A) (a), 5-HT 2A (ST 2A) (b) and 5-HT 3A (ST 3A) receptors (c and d). The somata of two horizontal cells immunoreactive for SR1A and SR2A receptors are denoted by asterisk (A and B). The bipolar cells perikarya immunoreactive for ST $3 \mathrm{~A}$ receptor are denoted by 5 white colored letters "B", while the perikaryon of an amacrine cell is denoted by "A". Numerous puncta are stained approximately in the middle of IPL (S3), the continuity of this sublayer being supplemented by a small white line (c). Magnification of the most distal part of a section in (D) allows the glial staining to be followed in more details. The retinal layers are as follows: PE - pigment epithelium and outer segments of photoreceptors; OLM - outer limiting membrane; ONL - outer nuclear layer; OPL - outer plexiform layer; INL - inner nuclear layer; IPL - inner plexiform layer; GCL - ganglion cell layer; ILM - inner limiting membrane. Scale bar: $\mathrm{a}-20 \mu \mathrm{m} ; \mathrm{b}-20 \mu \mathrm{m} ; \mathrm{c}-30 \mu \mathrm{m} ; \mathrm{d}-20 \mu \mathrm{m}$.

The SR3A-immunoreacrivity in the frog retina was expressed predominantly in the proximal part of the retina (Fig. 6A). The IPL was visually subdivided into 2 sublayers - distal and proximal. A row of amacrine cells were located immediately above the IPL. Two different sizes of their cell bodies could be distinguished. Ganglion cells were also stained. The Müller cells' most proximal parts, called "end-feet", which participate in the formation of the inner limiting membrane (ILM) were visualized as well. It was interpreted as a sign of glial staining and a probable participation of 5-HT3A receptor in neuro-glial interaction.

In the turtle retina the 5-HT3A receptor was expressed very well in the nuclear layers INL and GCL, where numerous perikarya were brightly stained. In INL, labels in the bipolar cells perikarya and their oblique axons were the most prominent feature in most of the sections (Fig. 5C). In other sections, however, the OPL staining was the most prominent feature. Very often, repeating "OPL modules", located at certain distance from one another, could be seen. The perikarya of the horizontal cells, whose processes participated in the formation of these modules, were also visualized. Surprisingly, at the background of predominantly nuclear staining, in one of the sections labels in the IPL were found (Fig. $5 \mathrm{C}$ ). They formed a bar of puncta located approximately at the IPL $\mathrm{S}_{3}$ sublayer. In addition to the synaptic staining, well expressed glial staining was visualized in some sections. It was represented by visualization of the Müller cells' processes and the outer and inner limiting membranes as well (Fig. 5D).

The SR4-antibody, directed to 5-HT4 receptor, in the frog retina caused bright staining in both plexiform layers and the photoreceptor layer (Fig. 6B). A clear-cut synaptic staining with single amacrine cells bodies, almost embedded in the IPL, was evident. On the contrary, we did not find any 
synaptic staining in the turtle retina. Single amacrine cells bodies and several signs for glial staining were the prominent features of the turtle retina SR4-R immunoreactivity.

The SR5A-antibody directed to 5-HT5A receptor caused well expressed staining in the frog retina, demonstrated by labels in both plexiform layers and the photoreceptors (Fig. 6C). In addition to the synaptic staining in OPL and IPL, glial localization of the receptor was also present. It was expressed by visualization of both retinal membranes, the OLM and ILM. Single perikarya of amacrine, ganglion and horizontal cell bodies were also noticed. In the turtle retina the antibody directed to 5-HT5A receptor caused both neuronal and glial staining (Fig. 7A). The neuronal staining was expressed by visualization of both synaptic layers and the perikarya of several subtypes of neurons in the INL and GCL. The visualization of both limiting membranes was interpreted as a sign for glial localization of the receptor.

The SR6-immunoreacrivity in the frog retina repeated the pattern of imminostaining from the previous studies. The antibody, directed to the 5-HT6 receptor, caused well expressed staining in both plexiform layers and photoreceptors (Fig. 7B). A tendency for visualization of ILM was noticed as well. In the turtle retina we found very rich staining in the OPL (Fig. 7C). Subdivision of the layer in two levels could be clearly seen. A great number of horizontal cells' perikarya was visualized, all of them being in close relations to the OPL. At least two different types of perikarya were distinguished in INL, most probably belonging to bipolar and amacrine cells. The visualization of the so called orthogonal array of particles, distal parts of the turtle retina Müller cells, was a sign for glial localization of the 5HT6 receptor.

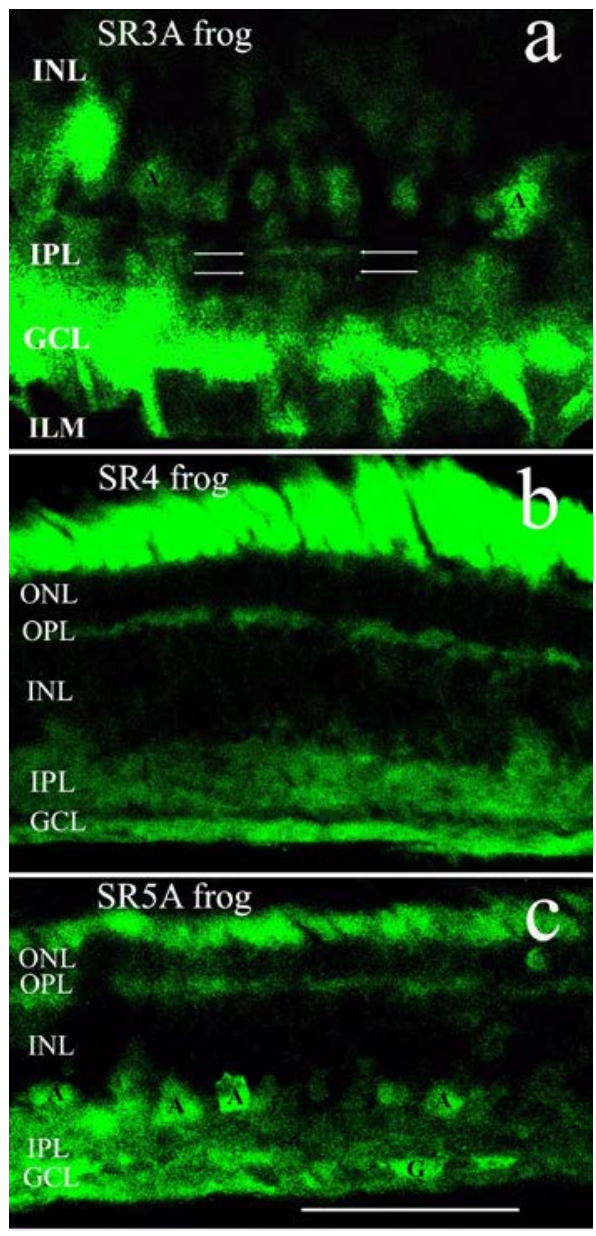

Figure 6. Photomicrographs of vertical sections of frog retina, immunolabeled for 5-HT 3A (ST 3A) (a), 5-HT 4A (ST 4A) (b) and 5-HT 5A (ST 5A) receptors (c). The ST 3A- immunoreactivity in (a) is represented by the somata of several different cells types located in the lower part of INL. In IPL, two bars of synaptic labeling can be followed, each denoted by two arrows oriented to each other to supplement the mixing parts of the bar. The end-feet of 
Müller cells seen between GCL and ILM are a sign of glial staining. The ST 4A-immunoreactivity (b) and ST 5Aimmunoreactivity (c) are expressed by diffuse synaptic staining in both plexiform layers. Labels in photoreceptors and the ganglion cells axons are also present. Several amacrines' (A) and ganglion (G) cells bodies are denoted which are supposed to be ones of the main participants as postsynaptic partners in the IPL synapses. All other indications are as in Fig. 5. Scale bar: a $-50 \mu \mathrm{m} ; \mathrm{b}-55 \mu \mathrm{m}$; c- $65 \mu \mathrm{m}$.

The SR7-immunoreacrivity in the frog retina had both neuronal and glial character Fig. 7D). The outer and the inner plexiform layers were very well stained. Single cells in the INL were marked. Parts of the OLM were also visualized. In the turtle retina, staining in all retinal layers was present (Fig. 7E). Very rich staining in the OPL was evident. A subdivision of the layer into two levels, very similar to those seen in the SR6 antibody's staining, could be noticed. A diversity of numerous perikarya in the INL, belonging to horizontal, bipolar and amacrine cells, could be seen. The IPL was diffusely marked, but no clear division in sublayers was noticed. The glial staining was demonstrated in the OLM.

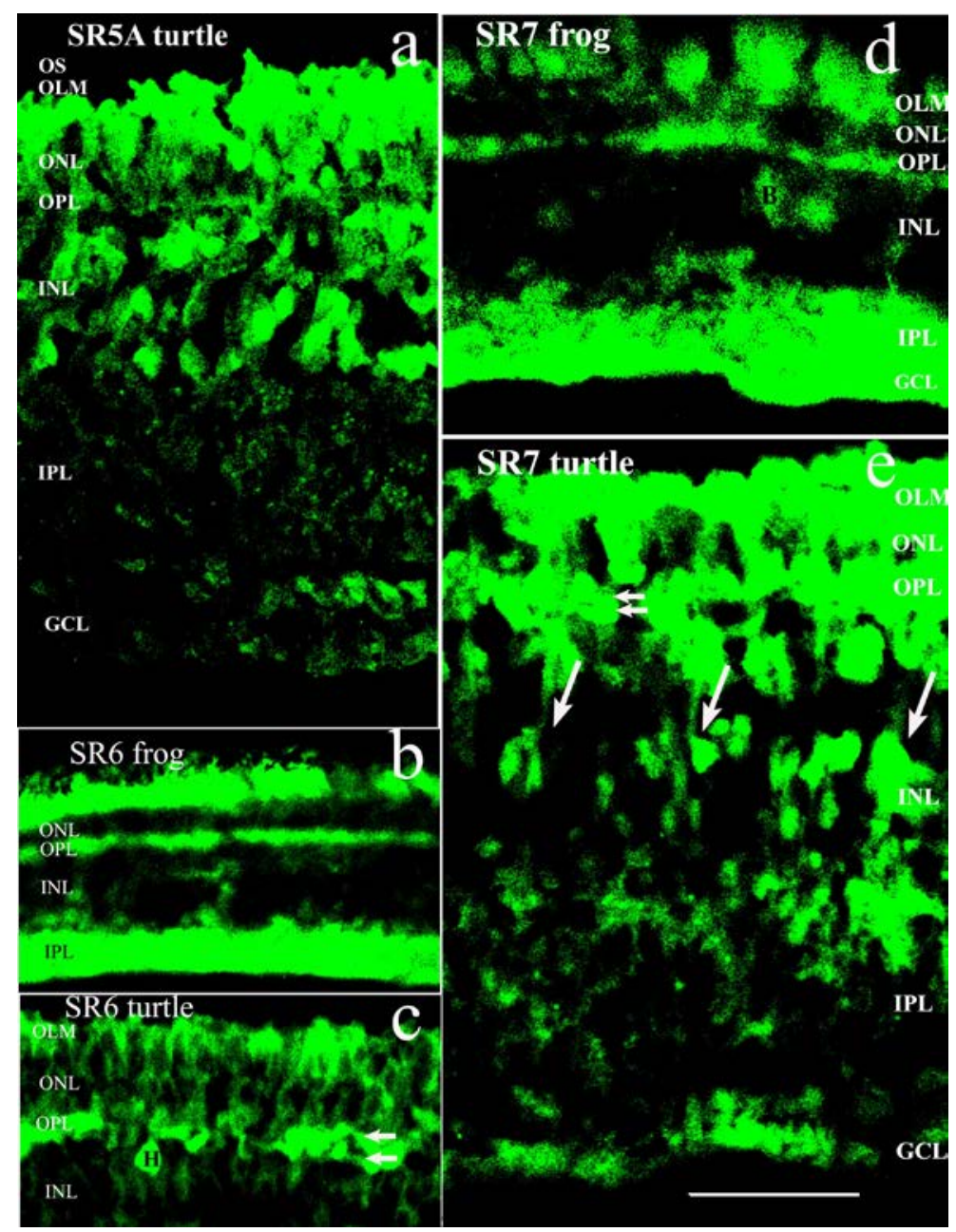

Figure 7. Photomicrographs of vertical sections of frog and turtle retinas immunolabeled for 5-HT 5A (ST 5A) (a), 5-HT 6 (ST 6) (b and c) and 5-HT 7 (ST 7) receptors (d and e). All three serotonin receptors show well expressed synaptic staining in both plexiform layers. The turtle ST-6 and SR-7 receptors immunoreactivities in the OPL seem to be localized in two sublayers denoted by two small parallel arrows (c and e). A horizontal cell's perikaryon (c) and the perikaryon of a bipolar cell $(\mathrm{d})$ are denoted by " $\mathrm{H}$ " and "B" respectively. By means of three large parallel to each other oblique arrows the projection of bipolar cells axons is shown (e). The indications are as follows: OS outer segments of photoreceptors; OLM - outer limiting membrane; ONL - outer nuclear layer; OPL - outer 
plexiform layer; INL - inner nuclear layer; IPL - inner plexiform layer; GCL - ganglion cell layer; ILM - inner

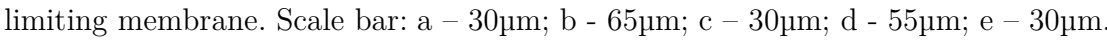

\subsection{Double Labeling Studies}

Necessity of verification of the different classes of retinal neurons emerged since the TrypH- and 5-HT receptors' immunoreactivities were very well expressed both in the frog and turtle retinas, being widely spread among several retinal classes of neurons. For the purpose of screening the cell classes, we chose two antisera towards calretinin and calbindin, belonging to the calcium binding proteins: Their distribution in the retinas of the different species is studied by a great number of authors [43, 44, 45]. Photomicrographs representing the calretinin (CR) and calbindin (CB) distribution in our experiments are shown in Fig. 8. As can be seen in the figure, we found $\mathrm{CR}$ in numerous horizontal, bipolar and amacrine cells. Single cells in GCL were also labeled. Both plexiform layers and photoreceptors were very well expressed as well. The CB staining was also expressed in several retinal classes. Comparing it to the CR staining, an increase of the number of the bipolar cells stained can be noticed. Our data are in agreement with the data obtained by other authors on the same type [43] or on closely related type of retina $[44]$.

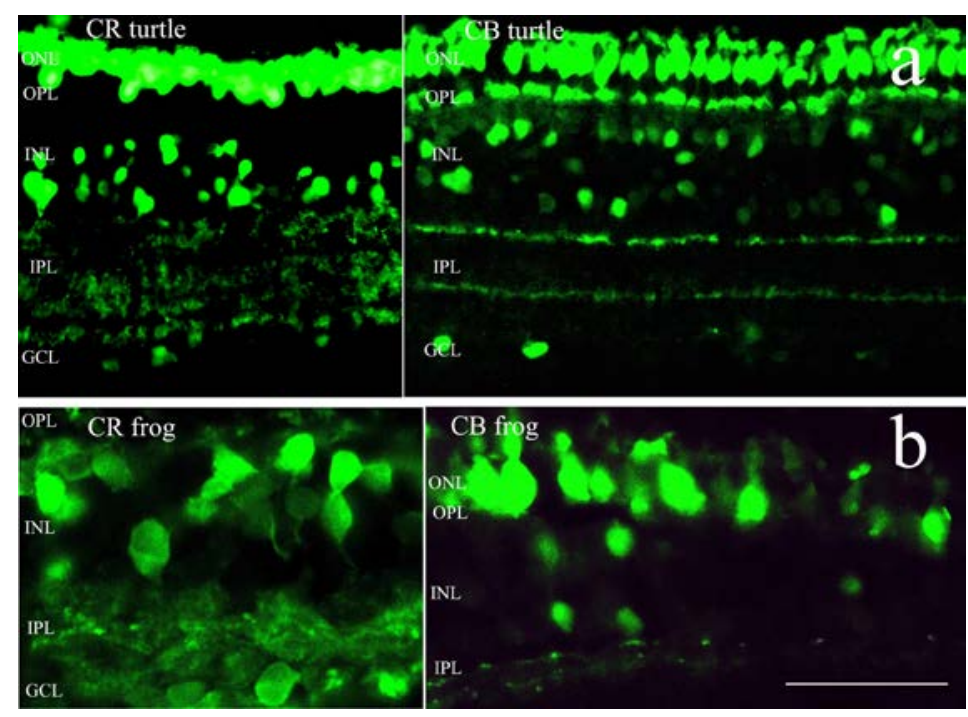

Figure 8. Photomicrographs of four different vertical sections of turtle (horizontal panel a) and frog retinas (horizontal panel b), immunolabeled for calretinin (left) and calbindin (right). The indications are as in Fig. 7. Scale bar: $\mathrm{a}-60 \mu \mathrm{m} ; \mathrm{b}-50 \mu \mathrm{m}$.

In our double labeling experiments we combined Calbindin antibody (red) and TrypH one (green), the results of which are represented in Fig. 9. A great number of colocalizations among different cell classes: amacrines, bipolar cells etc., was seen, which showed that Tryptophan hydroxilase, the rate limiting enzyme in the serotonin synthesis, is not exclusively limited to a subgroup of amacrine cells.

We also made double labeling of one and the same retinal section with anti-TrypH antibody (green) and anti-serotonin transporter antibody (STT, SERT) (red)(Fig. 10). We found again numerous colocalizations in different cell classes, which showed several different types of neurons: amacrines, bipolar cells and horizontal cells, possessed both tryptophan hydroxilase and serotonin transporter.

\section{Discussion}

Our immunocytochemical results show that the serotoninergic neurotransmission is widely represented and very well expressed in the frog and turtle retinas, two of the lower vertebrate animals. According to 
our data, tryptophan hydroxylase - the rate limiting enzyme in the synthesis of serotonin and the serotonin receptors studied - are widely distributed in several different types of neurons all over the retina, and in the retinal glia as well. Details of their distribution and their putative functions will be discussed in details further.

\subsection{Serotoninergic Neurons}

The immunocytochemical analysis of serotonin distribution in the retina involves application of two types of antibodies. Most often, antibodies directed to serotonin (anti 5-HT antibodies) are used, and by means of this technique the retinal serotonin is proved to be expressed predominantly in the amacrine and bipolar cells $[13,14,46,47]$. To a lesser extent, serotonin is found in some ganglion cells as well [48]. Another possibility to mark serotonin is to use antibodies directed to the enzymes, responsible for its synthesis: at first place this is tryptophan hydroxylase (TrypH), which is known to be the key enzyme in serotonin and melatonin formation. At present, the prevailing view is that TrypH is present only in a subgroup of amacrine cells (called "serotonin-synthesizing" neurons), while the "serotoninergic" bipolar cells do not contain TrypH and therefore do not synthesize serotonin, being able only to transport and destroy it ("serotonin accumulating" neurons) [18, 24, 46, 47].

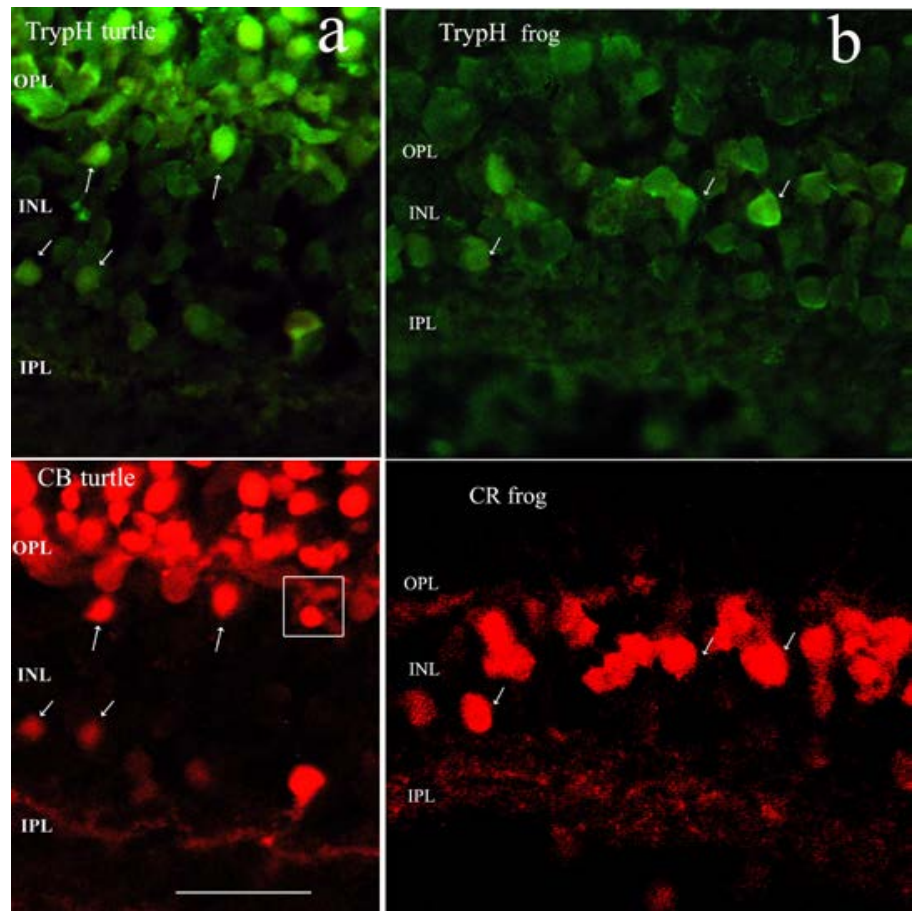

Figure 9. Photomicrographs of vertical sections of frog and turtle retinas double labeled for tryptophanhydroxilase $($ TrypH) and calretinin $(\mathrm{CR})$ and calbindin(CB). The turtle retinal section (vertical panel a) is double labeled for TrypH (green) and CB (green), the frog one (vertical panel b) - for TrypH (green) and CR (green). Colocalizations are denoted by arrows. The white rectangle in b denotes a region without colocalization. Scale bar: $\mathrm{a}-35 \mu \mathrm{m} ; \mathrm{b}-$ $40 \mu \mathrm{m}$

We did not find detailed information about the exact experimental procedures and the respective antibodies used in the above cited literature. However, the partial information we succeeded to collect showed that in most of the cases an antibody directed to phenylalanine hydroxylase was used, which was assumed to label tryptophan hydroxylase as well. For that reason we decided to test immunocytochemically the new antibodies, developed to specifically label tryptophan hydroxylase $(\mathrm{TrypH})$, the rate limiting enzyme in serotonin synthesis. Surprisingly, in the frog and turtle retinas we observed strong TrypH - immunoreactivity, expressed not only in amacrines, but in bipolar cells as well. It is known, that turtle retina and its bipolar cells, in particular, are studied very thoroughly $[15-17$, 
19, 49]. This helped us a lot in the identification of TrypH-immunoreactive bipolar cells in our study. Their appearance, distribution across the retina and synaptic contacts formed in both plexiform layers observed in our experiments coincided entirely with the descriptions of the turtle bipolar cells made by other authors $[15,49]$. The TrypH-immunoreactive bipolar cells in our study had Landolt' clubs (located in OPL), pyriform perikarya (located in distal INL) and axons projecting through INL toward the IPL (Fig. 2). The bipolar cells axons profiles differed across the retinal surface. At the visual streak and in the most peripheral part of retina they crossed INL in perpendicular direction. In between these regions the axons took horizontal or oblique direction toward IPL. The same bipolar cells profiles have been observed by other authors who had studied serotonin immunoreactivity in turtle retina [16, 17]. In our double labeling experiments with anti-calbindin and anti-TrypH antibodies we found numerous bipolar cells colocalizations

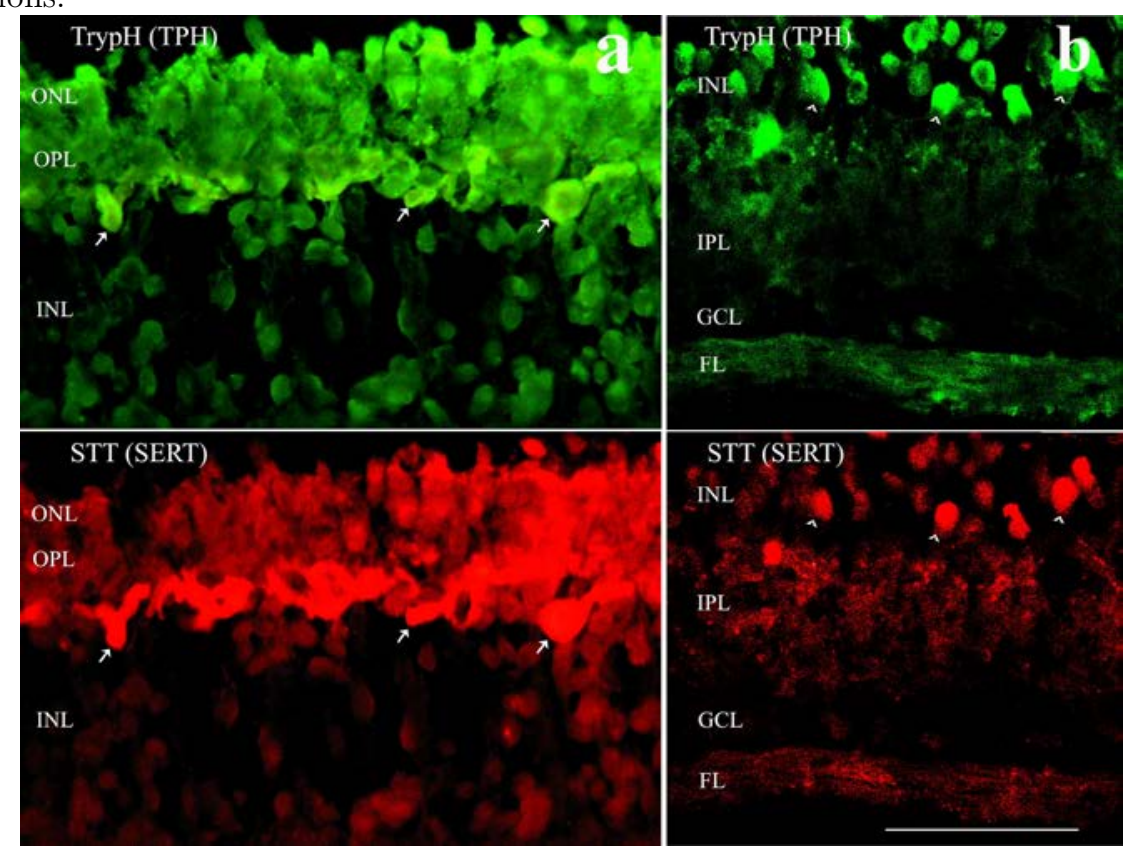

Figure 10. High power photomicrographs of two vertical sections of turtle retina each of which double labeled for tryptophanhydroxylase (TrypH, TPH) and serotonin transporter (STT, SERT). While the first section (vertical panel a) is represented by its distal layers, the second one (vertical panel b) is represented by its proximal layers predominantly. Part of colocalizations are denoted by arrows in the first section (panel a) and by arrowheads in the second one (panel b). Please, notice the colocalizations in the IPL, as well as the numerous nerve fibers, running in parallel in FL, which might be axons of the serotoninergic ganglion cells or axons of serotoninergic retinopetal neurons. The indications are as follows: ONL - outer nuclear layer; OPL - outer plexiform layer; INL - inner nuclear layer; IPL - inner plexiform layer; GCL - ganglion cell layer; FL - fibers layer. Scale bar: a - $30 \mu \mathrm{m}$; b - 40 $\mu \mathrm{m}$.

Our results on TrypH- immunoreactivity are in conjunction with the recent studies on the TrypH mRNA expression. It was definitely shown by RT-PCR that TrypH 1(TPH1), the "classical" TrypH mRNA is the prevalent form present in the retina [50]. TrypH 1 is demonstrated in the retinas of different species: rat [50], sea lamprey [51, 52], chicken [53] and Xenopus [55]. In all types of retinas studied [50 - 54], the TrypH1 mRNA is most abundant in the photoreceptors, which is in conjunction with the strong labeling of photoreceptors by the anti-TrypH antibody, observed in our experiments (Fig. 1, Fig. 2). Tryptophan hydroxylase here is needed for the local synthesis of serotonin, the precursor of melatonin. Both serotonin and melatonin levels here undergo diurnal rhythmic changes, as has been shown by many authors $[7,53,55]$. In addition to photoreceptors level, the TrypH1 mRNA is proved to exist in the vitreal portion of the inner nuclear layer as well, and to a lesser extent in the ganglion cells layer $[50,52,53]$. These facts are in conjunction with our observations about the presence of TrypHimmunoreactive bipolar cells, as well as with the presence of single TrypH- immunoreactive horizontal and ganglion cells (Fig. 2). The previous failures to demonstrate them by other authors might be due to 
the antibodies used, or to the location of the retinal sections, as data exist that the TrypH-synthesizing neurons are not equally distributed along the retina.

In summary, according to our results, frog and turtle retinas possess several types of tryptophan hydroxylase immunoreactive cells, the main being the amacrine and the bipolar ones. Some horizontal and some ganglion cells are also TrypPH-immunoreactive. It may be supposed that the majority of them possess serotonin transporter protein embedded in their cell membranes [41], as was shown in our present double labeling experiments (Fig. 10).

\subsection{Serotonin Receptors}

Serotonin receptors are divided into seven large groups, each of which is subdivided into many subgroups [56, 57]. We studied only seven of them: 5-HT1A, 5-HT2A, 5-HT3A, 5-HT4, 5-HT5A, 5-HT 6 and 5-HT 7. From above mentioned receptors, only 5-HT3A is an ionotropic receptor, while all the others are metabotropic [57].

Our study shows that all the receptors mentioned are very well expressed in the frog and turtle retinas. Both plexiform layers - OPL and IPL, locations where the majority of synaptic contacts between the retinal neurons take place, were heavily labeled by the antibodies directed to the serotonin receptors 5-HT1A, 5-HT2A, 5-HT3A and 5-HT5A (Fig. 4, 5, 6A and 6C). The synaptic staining was better expressed in the frog retina, as compared to the turtle one, where numerous perikarya were stained very often, without staining in both plexiform layers. However, while in the frog retina the 5-HT receptors staining in IPL usually had more or less diffuse character, two or three distinct sublayers were identified in the turtle retina. The antibodies to the above mentioned receptors usually stained the upper, middle and lower parts of IPL that might be supposed to correspond to the S1, S3 or S5 sublayers, the same ones where both serotoninergic amacrine cells and serotoninergic bipolar cells were shown to form their synapses (Fig. 1 and Fig. 2). Due to the visualization of different perikarya in the nuclear layers, belonging to amacrine, bipolar and ganglion cells, we have good ground to suppose that the 5-HT1A, 5-HT2A, 5-HT3A and 5-HT5A receptors mediate neurotransmission between the serotoninergic amacrine cells and other amacrines, bipolar and ganglion cells, as well as the neurotransmission between the serotoninergic bipolar cells and amacrine and ganglion cells. Synaptic contacts between the amacrine cells are numerous. It is known that the different subtypes of amacrine cells form the so called "serial synapses" between each other. Our observation about the presence of a great number of serial synapses between the serotoninergic amacrine cells and other amacrine cells is in good agreement with the observations of other authors [13, 16, 17]. We also showed in our study that the 5-HT1A, 5-HT3A and 5-HT5A receptors mediate the serotoninergic transmission to the ganglion cells. Serotonin effects on the ganglion cells activity are already demonstrated by means of electrophysiological methods [25]. Further studies are needed in order a differentiation to be made between the two types of serotoninergic influences on the ganglion cells activity. As concerns the synapses between the serotoninergic amacrine cells and bipolar cells, called "feedback synapses", our results show that the transmission here is most probably mediated by the serotonin receptors 5-HT3A and 5-HT5A. The presence of such type of serotoninergic synapse (without identification of the receptors) is pointed out by Hurd and Eldred as well [13].

As already mentioned, we did not find in the literature any data regarding the retinal localization and the possible function of the 5-HT4, 5-HT6 and 5-HT7 receptors, although they have been proved to exist in the CNS. To the best of our knowledge, our study is the first to prove immunocytochemically their presence in the retina (Fig. 6B, Fig.7 B - E). All three receptors were well expressed in the frog and turtle, demonstrating both neuronal and glial localization. The antibodies to SR6 and SR7 caused rich staining in the whole retina, although some preferences to distal retinal layers could be denoted (Fig. 7). At the range of OPL, subdivision into two sublayers was evident (Fig. 7E). Labels in the OPL, together with the labels of horizontal and bipolar cells' perikarya, give us good ground to assert that serotonin receptors 5-HT 6 and 5-HT 7 do participate in the neurotransmission between the photoreceptors - on the one hand, and the horizontal and bipolar cells in the frog and turtle retina - on the other hand. As the all three above mentioned structures show tryptophane hydroxylase immunoreactivity as well, it cannot be excluded that some of the receptors are postsynaptic, while others are presynaptic. 
In summary: According to our data, several different sources of serotonin are present in the frog and turtle retinas. The main source is represented by the serotoninergic amacrine and serotoninergic bipolar cells, and an additional, smaller one - by single horizontal and ganglion cells. Photoreceptors also show TrypH- immunoreactivity, as serotonin synthesized here is most probably precursor of melatonin.

Our experiments also showed that serotonin is released both in a "classic manner" (in the conventional synapses inside the both plexiform layers), and by the numerous varicosities along the length of the neuronal processes (see the varicosities of the amacrine cells in Fig. 2C and Fig. 2D). In the last case, the chemical substance may freely diffuse between the neuronal processes to influence the receptors in the vicinity, which is described by some authors as "volume conduction" [1]. Our idea is that in this case serotonin works rather as a neuromodulator, than as a neurotransmitter. The potential neuromodulatory function of serotonin is in agreement with the data of other authors who have shown that serotonin is able to regulate the balance between on- and off- responses [32] and may be involved in the binocular perception as well [58].

We also showed a great variety of different types of serotonin receptors widely distributed in the retina. The numerous receptors give us good ground to suppose that retina is extremely sensitive to serotonin. An impression appears that the retina is designed to be able to "catch" each serotonin molecule released. Are the retinal serotoninergic cells the sole serotonin source in the retina? As has been shown in different types of retinas [59: goldfish and rat, 60: monkey], several large-diameter serotoninergic retinopetal axons are followed to enter through the optic disc inside the retina. Their propagation has been demonstrated immunocytochemically and the data obtained show that some of them, branching extensively, terminate in the GCL, while others reach the distal parts of IPL and branch in the INL. These retinopetal axons are proved to possess a lot of varicose structures [60], which is indicative for a modulatory effect. We also observed TrypH-immunoreactive axons located in the most proximal part of the retina. Positioned in parallel to each other, they formed bundle of TrypHimmunoreactive fibers (Fig. 2, Fig. 9), some of which might belong to serotoninergic retinopetal neurons. Taking into account the large number of serotonin receptors spread in the INL, it may be supposed that serotonin released by the retinopetal axons freely diffuses and binds to these receptors, exerting its effect as a neuromodulator. The negative neuromodulatory effect of serotonin on GABA $p 1$ receptors has already been demonstrated on Xenopus laevis oocytes [61]. This is in conjunction with our understanding that serotonin serves not only as a neurotransmitter, but as a neuromodulator of the retinal function as well. Its neuroprotective role cannot be omitted as well [62]. The extensive representation of 5-HT1A receptors in the retina may have also protective character, as it is known that agonists of this receptor save the retina from severe photo-oxidative stress [62].

\section{Conclusion}

The results obtained give us good ground to suggest that the tryptophan hydroxylase immunoreactivity in the retina, and the serotonin retinal sources respectively, are more numerous than was previously believed, which is in agreement with the recent studies on the TrypH mRNA expression in retina [51, 62]. The serotonin receptors 5-HT1A-, 5-HT2A-, 5-HT3A- , 5-HT4-, 5-HT5A-, 5-HT6- and 5-HT7immunoreactivity was also very well expressed. To best of our knowledge, our data about the serotonin receptors 5-HT6 and 5-HT7 are the first immunocytochemical data obtained until now; they suggest that these serotonin receptors are mainly involved in the distal retina information processing. Serotoninergic system is involved in the glial function as well.

Acknowledgments. The study was supported by the Medical Science Council of the Medical University Sofia, Bulgaria (Research Grant \# 38/2014 to Liliya Vitanova). During the study all institutional, national and EU guidelines for the care and use of laboratory animals were followed.

The authors Liliya Vitanova, Desislava Zhekova and Petia Kupenova, all of them working at the Department of Physiology in the Medical University Sofia, Bulgaria, declare that they have no conflicts of interests.

Author's contributions: LV carried out the experiments, processed the experimental data and wrote the manuscript; DZ collected part of references and participated in the experiments with serotonin 
transporter antibody, PK participated in discussions and final processing of the manuscript. All authors read and approved the final manuscript.

\section{References}

1. K. Fuxe, A. Dahlström, M. Höistad, D. Marcellino, A. Jansson, A. Rivera, Z. Diaz-Cabiale, K. Jacobsen, B. Tinner-Staines, B. Hagman, G. Leo, W. Staines, D. Guidolin, J. Kehr, S. Genedani, N. Belluardo, and L. F. Agnati, "From the Golgi-Cajal mapping to the transmitter-based characterization of the neuronal networks leading to two modes of brain communication: wiring and volume transmission", Brain Research Revews, vol. 55, no. 1, pp. 17-54, 2007.

2. J. Lavoie, P. Illiano, T.D. Sotnikova, R.R. Gainetdinov, J.M. Beaulieu, and M. Hébert, "The electroretinogram as a biomarker of central dopamine and serotonin: potential relevance to psychiatric disorders", Biological Psychiatry, vol. 75, no. 6, pp. 479-86, 2014.

3. P. Thampi, H.V. Rao, S.K. Mitter, J. Cai, H. Mao, H. Li, S. Seo, X. Qi, A.S. Lewin, C. Romano, and M.E. Boulton, "The 5HT1a receptor agonist 8-Oh DPAT induces protection from lipofuscin accumulation and oxidative stress in the retinal pigment epithelium". PLoS One, vol. 7, no. 4, e34468, 2012.

4. J. Shen, K. Ghai, P. Sompol, X. Liu, X. Cao, P.M. Iuvone, and K. Ye, "N-acetyl serotonin derivatives as potent neuroprotectants for retinas", Proceedings of the National Academy of Sciences of the United States of America, vol. 109, no.9, pp. 3540-3545, 2012.

5. N.T. Osborne, D Nesselhut, A. Nikolas, S. Patel, and A.C. Cuello, "Serotonin-containing neurones in vertebrate retinas", Journal of Neurochemistry, vol. 39, no. 6, pp. 1519 -1528, 2012.

6. M. Bennis and C. Versaux-Botteri, "Catecholamine-, indoleamine-, and GABA-containing cells in the chameleon retina", Visual Neuroscience, vol. 12, no. 4, pp. 785 -792, 1995.

7. N.S. Fosser, A. Brusco, and H Ríos, "Darkness induced neuroplastic changes in the serotoninergic system of the chick retina", Brain Research. Developmental Brain Research, vol. 160, no. 2, pp. 211-218, 2005.

8. T. Hayashi, G. Hirose, M. Kawata, and Y. Sano, "Cytological features of serotonin-containing neurons and their processes in the retina of the carp (Cyprinus carpio): An immunohistochemical study using flat-mount preparations", Histochemistry, vol. 84, no. 4-6, pp. 423-425, 1986.

9. R.E. Marc, "Spatial organization of neurochemically classified interneurons of the goldfish retina-I. Local patterns", Vision Research, vol. 22, no. 5, pp. 589-608, 1982.

10.W. Skrandies and H. Wässle, "Dopamine and serotonin in cat retina: electroretinography and histology", Experimnental Brain Research, vol. 71, no. 2, pp. 231-240, 1988.

11.R. Bragadóttir, M. Kato, and S. Jarkman,"Serotonin elevates the c-wave of the electroretinogram of the rabbit eye by increasing the transepithelial potential", Vision Research, vol. 37, no. 18, pp. 2495-2503, 1997.

12.B. Ehinger, "Connexions between retinal neurons with identified neurotransmitters", Vision Research, vol. 23, no. 11, pp. 1281-1289, 1983.

13.L.B. Hurd 2nd and W.D. Eldred, "Synaptic microcircuitry of bipolar and amacrine cells with serotonin-like immunoreactivity in the retina of the turtle, Pseudemys scripta elegans", Visual Neuroscience, vol. 10, no. 3, pp. 455-471, 1993.

14.J. Vígh, T. Bánvölgyi, and M. Wilhelm, "Amacrine cells of the anuran retina: morphology, chemical neuroanatomy, and physiology", Microscopy Research and Technique, vol. 50, no. 5, pp. 373-383, 2000.

15.P. Witkovsky, W. Eldred, and H.J. Karten, "Catecholamine- and indoleamine-containing neurons in the turtle retina", Journal of Comparative Neurology, vol. 228, no. 2, pp. 217-225, 1984.

16.R. Weiler and M. Schütte, "Morphological and pharmacological analysis of putative serotonergic bipolar and amacrine cells in the retina of a turtle, Pseudemys scripta elegans", Cell and Tissue Research, vol. 241, no. 2, pp. 373-382, 1985.

17.M. Schütte and R. Weiler, "Morphometric analysis of serotoninergic bipolar cells in the retina and it implications for retinal image processing", Journal of Comparative Neurology, vol. 260, no. 4, pp. 619-626, 1987.

18.M. Schütte, "Serotonergic and serotonin-synthesizing cells of the Xenopus retina", International Journal of Neuroscience, vol. 78, no.1-2, pp. 67-73, 1994. 
19.M. Tauchi, "Single cell shape and population densities of indoleamine-accumulating and displaced bipolar cells in Reeves' turtle retina", Proceedings of the Royal Society B: Biological Sciences, vol. 238, no. 1293, pp. 351-367, 1990.

20.I. Florén and A. Hendrickson, "Indoleamine-accumulating horizontal cells in the squirrel monkey retina", Investigative ophthalmology \& visual science, vol. 25, no. 9, pp. 997-1006, 1984.

21.H. Wässle and M.H. Chun, "Dopaminergic and Indoleamine-Accumulating Amacrine Cells Express GABA-Like lmmunoreactivity in the Cat Retina", The Journal of Neuroscience, vol. 8, no. 9, pp. 3383-3394, 1988.

22.B. Zhu, R. Gábriel, and C. Straznicky,"Serotonin synthesis and accumulation by neurons of the anuran retina", Visual Neuroscience, vol. 9, no. 3-4, pp. 377-388, 1992.

23.R. Gábriel, B.S Zhu, and C. Straznicky, "Synaptic contacts of serotonin-like immunoreactive and 5,7dihydroxytryptamine-accumulating neurons in the anuran retina", Neuroscience, vol. 54, no. 4, pp. 1103-1114, 1993.

24.K. Ghai, C. Zelinka, and A.J. Fischer, "Serotonin released from amacrine neurons is scavenged and degraded in bipolar neurons in the retina", Neurochemistry, vol. 111, no. 1, pp. 1-14, 2009.

25.S. Hidaka, "Serotonergic synapses modulate generation of spikes from retinal ganglion cells of teleosts", Journal of Integrative Neuroscience, vol. 8, no. 3, pp. 299-322, 2009.

26.S.C. Mangel and W.J. Brunken, "The effects of serotonin drugs on horizontal and ganglion cells in the rabbit retina", Visual Neuroscience, vol. 8, no. 3, pp. 213-218, 1992.

27.K. Pootanakit and W.J. Brunken, " 5-HT(1A) and 5-HT(7) receptor expression in the mammalian retina", Brain Research, vol. 87, no. 1-2, pp. 152-6, 2000.

28.M. Pennesi, J. Stoddard, K. Michaels et al, "Expression and Localization of Serotonin Receptor in the Mouse Retina", Investigative Ophthalmogy and Visual Science, vol. 53, e-abstract 6547, 2012.

29.K. Pootanakit, K.J. Prior, D.D. Hunter and W.J. Brunken, "5-HT2a receptors in the rabbit retina: potential presynaptic modulators", Visual Neuroscence, vol. 16, no. 2, pp. 221-230, 1999.

30.L. Han, Y. M. Zhong, and X.L. Yang,"5-HT2A receptors are differentially expressed in bullfrog and rat retinas: a comparative study", Brain Research Bulletin, vol. 73, no. 4-6, pp. 273-277, 2007.

31.K. Pootanakit and W.J. Brunken, "Identification of 5-HT (3A) and 5-HT (3B) receptor subunits in mammalian retinae: potential pre-synaptic modulators of photoreceptors", Brain Research, vol. 896, no. 1-2, pp. 77-85, 2001.

32.W.J. Brunken and X.T. Jin, "A role for 5HT3 receptors in visual processing in the mammalian retina", Visual .Neuroscience, vol. 10, no. 3, pp. 511-522, 1993.

33.S. Doly, J. Fischer, M.J. Brisorgueil, D. Vergé, and M. Conrath, "5-HT5A receptor localization in the rat spinal cord suggests a role in nociception and control of pelvic floor musculature", Journal of Comperative Neurology; vol. 476, no. 4, pp. 316-329, 2004.

34.G. García-Alcocer, A. Rodríguez, P. Moreno-Layseca, L.C. Berumen, J. Escobar, and R. Miledi, "Serotonin receptor 5-HT5A in rat hippocampus decrease by leptin treatment", Neuroscience Letters, vol. 486, no. 3, pp. 171-173, 2010.

35.D.E. Lorke, G. Lu, E. Cho, and D.T. Yew, "Serotonin 5-HT2A and 5-HT6 receptors in the prefrontal cortex of Alzheimer and normal aging patients", BMC Neuroscience, vol. 7:36, 2006.

36.M.S. Wai, D.E. Lorke, W.H. Kwong, L. Zhang, and D.T. Yew, "Profiles of serotonin receptors in the developing human thalamus", Psychiatry Research, vol. 185, no. 1-2, pp. 238-242, 2011.

37.M.A. Belenky and G.E. Pickard, "Subcellular distribution of 5-HT(1B) and 5-HT(7) receptors in the mouse suprachiasmatic nucleus". Journal of Comparative Neurology, vol. 432, no. 3, pp. 371-88, 2001.

38.B.N. Smith, P.J. Sollars, F.E. Dudek, and G.E. Pickard, "Serotonergic modulation of retinal input to the mouse suprachiasmatic nucleus mediated by 5-HT1B and 5-HT7 receptors", Journal of Biological Rhythms; vol 6, no. 1, pp. 25-38, 2001.

39.L. Vitanova, P. Kupenova, S. Haverkamp, E. Popova, L. Mitova, and H. Wässle, "Immunocytochemical and electrophysiological characterization of GABA receptors in the frog and turtle retina", Vision Research; vol. 41, no. 6, pp. 691-704, 2001.

40.R. Weiler and J. Ammermüller, "Immunocytochemical localization of serotonin in intracellularly analyzed and dye-injected ganglion cells of the turtle retina", Neuroscience Letters; vol. 72, no. 2, pp. 147-152, 1986. 
41.L. A. Vitanova and D. I. Zhekova, "Dopamine and serotonin transporters in frog and turtle retina: Immunofluorescent evidence", Comptes rendus de l'Academie bulgare des Sciences, vol. 68, no. 12, pp. 15771588,2015 .

42.U. Gether, P.H. Andersen, O.M. Larsson, and A. Schousboe, "Neurotransmitter transporters: molecular function of important drug targets", Trends in Pharmacological Sciences, vol. 27, no. 7, pp. 375-383, 2006.

43.N. Cuenca, S. Haverkamp, and H. Kolb, "Choline acetyltransferase is found in terminals of horizontal cells that label with GABA, nitric oxide synthase and calcium binding proteins in the turtle retina", Brain Research, vol. 878, no. 1-2, pp. 228-239, 2000.

44.J. Zhang, A.J. Zhang, and S.M. Wu, "Immunocytochemical analysis of GABA-positive and calretinin-positive horizontal cells in the tiger salamander retina", Journal of Comparative Neurology, vol. 499, no. 3, pp. 432-441, 2006.

45.S. Haverkamp and H. Wässle, "Immunocytochemical Analysis of the Mouse Retina", Journal of Comparative Neurology, vol. 424, pp. 1-23, 2000.

46.R.E. Marc, W.L. Liu, K. Scholz, and J.F. Muller. "Serotonergic and serotonin-accumulating neurons in the goldfish retina",.Journal of Neuroscience, vol. 8, no. 9, pp. 3427-5450, 1988.

47.M. Wilhelm, B. Zhu, R. Gábriel, and C. Straznicky, "Immunocytochemical identification of serotoninsynthesizing neurons in the vertebrate retina: a comparative study". Experimental Eye Research, vol. 56, no. 2, pp. 231-240, 1993.

48.Q. Liu and E.A. Debski, "Serotonin-like immunoreactivity in the adult and developing retina of the leopard frog Rana pipiens", Journal of Comparative Neurology; vol. 338, no. 3, pp. 391-404, 1993.

49.B. Ehinger, O.P. Ottersen, J. Storm-Mathisen, and J.E. Dowling, "Bipolar cells in the turtle retina are strongly immunoreactive for glutamate", Proceedings of the National Academy of Sciences of USA, vol. 85, no. 21, pp. 8321-8325, 1988.

50.J. Liang, J.H. Wessel 3rd, P.M. Iuvone, G. Tosini, and C. Fukuhara, "Diurnal rhythms of tryptophan hydroxylase 1 and 2 mRNA expression in the rat retina", Neuroreport, vol. 15, no. 9, pp. 1497-1500, 2004.

51.M.E. Cornide-Petronio, R. Anadón, M.C. Rodicio, and A. Barreiro-Iglesias, "The sea lamprey tryptophan hydroxylase: new insight into the evolution of the serotonergic system of vertebrates", Brain Structure \& Function, vol. 218, no. 2, pp. 587-593, 2013.

52.M. E. Cornide-Petronio, R. Anadón, A. Barreiro-Iglesias, and M.C. Rodicio, "Tryptophan hydroxylase and serotonin receptor 1A expression in the retina of the sea lamprey", Experimental Eye Research, vol. 135, pp. 8187,2015

53.N.W. Chong, V.M. Cassone, M. Bernard, D.C. Klein, and P.M. Iuvone, "Circadian expression of tryptophan hydroxylase mRNA in the chicken retina", Brain Research Molecular Brain Research, vol. 61, no. 1-2, pp. 243$250,1998$.

54.C.B. Green, G.M. Cahill, and J.C. Besharse, "Tryptophan hydroxylase is expressed by photoreceptors in Xenopus laevis retina”.,Visual Neuroscience, vol 12, no. 4, pp. 63-70, 1995.

55.E. Chanut, J. Nguyen-Legros, B. Labarthe, J.H. Trouvin, and C. Versaux-Botteri, "Serotonin synthesis and its light-dark variation in the rat retina", Journal of Neurochemistry, vol. 83, no. 4, pp. 863-869, 2002.

56.D.E. Nichols and C.D. Nichols, "Serotonin receptors", Chemical Reviews, vol. 108, no. 5, pp. 1614-1641, 2008.

57.M. Pytliak, V. Vargová, V. Mechírová, and M. Felšöci, "Serotonin receptors - from molecular biology to clinical applications", Physiological Research, vol. 60, no. 1, pp. 15-25, 2011.

58.M. Schütte and P. Witkovsky, "Serotonin-like immunoreactivity in the retina of the clawed frog Xenopus laevis", Journal of Neurocytology; vol. 19, no. 4, pp. 504-518, 1990.

59.L. Lima and M. Urbina, "Serotonergic projections to the retina of rat and goldfish", Neurochemistry, vol. 32, no. 2, pp. 133-141, 1998.

60.M.J. Gastinger, A.S. Bordt, M.P. Bernal, and D.W. Marshak, "Serotonergic retinopetal axons in the monkey retina", Current Eye Research, vol. 30, no. 12, pp. 1089-1095, 2005.

61.L. D. Ochoa-de la Paz, A. Estrada-Mondragón, A. Limón, R. Miledi, and A. Martínez-Torres, "Dopamine and serotonin modulate human GABAp1 receptors expressed in Xenopus laevis oocytes", ACS Chemical Neuroscience, vol. 3, no. 2, pp. 96-104, 2012. 
62.R.J. Collier, Y. Patel, E.A. Martin, O. Dembinska, M. Hellberg, D.S. Krueger, M.A. Kapin, and C. Romano, "Agonists at the serotonin receptor 5-HT(1A) protect the retina from severe photo-oxidative stress", Investigative Ophthalmology and Visual Sciences, vol. 52, no. 5, pp. 2118-2126, 2011.

\section{Appendix}

Complementary material to the paper with the abbreviations used

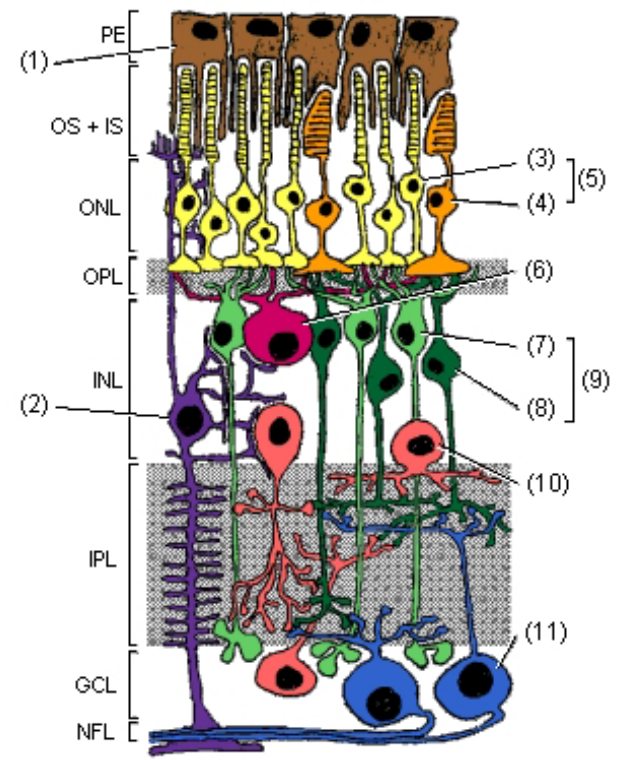

The yellow arrows show the direction in which light moves.

1 - pigment epithelium; 2 - Müller cell; 3 - rod; 4 - cone; 5 - photoreceptors; 6 - horizontal cell; 7 - on - bipolar cell; 8 - off - bipolar cell; 9 - bipolar cells; 10 - anacrine cell; 11 - ganglion cell

PE - pigment epithelium; OS and IS - outer and inner segment of photoreceptors; ONL - outer nuclear layer; OPL - outer plexiform layer; INL - inner nuclear layer; IPL - inner plexiform layer; GCL ganglion cell layer; NFL or FL - nerve fibers layer.

Source of the retina illustration: The Internet site of the Max-Planck-Inst. Brain Res. Frankfurt, Germany, 2003 (by permission). 